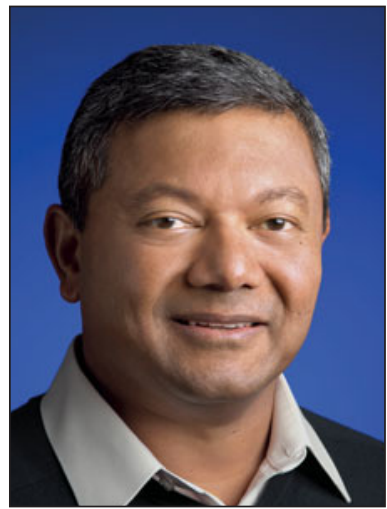

Arun Majumdar of Google to give plenary address on sustainable energy at 2013 MRS Spring Meeting nomic growth since the beginning of the industrial revolution. Majumdar says society's use of energy in the 21 st century must also be sustainable. In his presentation, "A New Industrial Revolution for a Sustainable Energy Future,” Majumdar will provide a techno-economic snapshot of the current energy landscape and identify several research and development opportunities and challenges, particu- larly related to materials research and engineering, to create the foundation for this new industrial revolution.

Currently a vice president for energy at Google, Majumdar is driving Google. org's energy initiatives and advising the company on its broader energy strategy. Prior to joining Google, Majumdar was the founding director of the US Advanced Research Projects Agency-Energy (ARPA-E)

MRS to innovate the future of energy technologies. During part of this time, he also served as Acting Under Secretary of Energy and a senior advisor to the Secretary of Energy. In this role, he was responsible for integrating technologies and policies across all of the Department of Energy along techno-economic sectors to maximize leveraging of federal funding and to accelerate technology transition from research to markets. world's increasing prosperity and eco-

\section{John E. Rabolt
and D. Bruce Chase
to receive MRS
Innovation in Materials
Characterization Award \\ John E. Rabolt
and D. Bruce Chase
to receive MRS
Innovation in Materials
Characterization Award \\ John F. Rabolt
and D. Bruce Chase
to receive MRS
Innovation in Materials
Characterization Award \\ John F. Rabolt
and D. Bruce Chase
to receive MRS
Innovation in Materials
Characterization Award \\ John F. Rabolt
and D. Bruce Chase
to receive MRS
Innovation in Materials
Characterization Award}
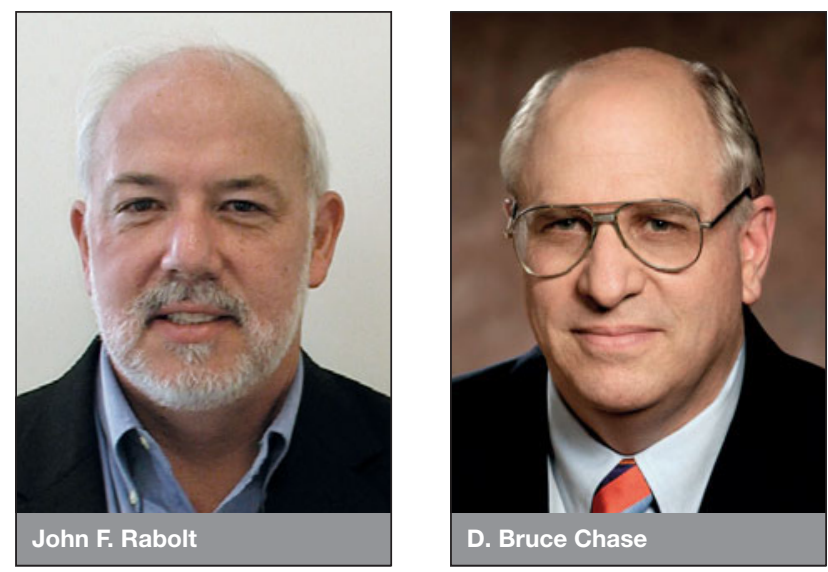

\begin{abstract}
Tohn F. Rabolt and D. Bruce Chase of $\mathcal{J}$ the University of Delaware have been honored with the Materials Research Society Innovation in Materials Characterization Award for their "development of Fourier Transform Raman Spectroscopy and the demonstration of its utility for examining the chemical structure and properties of organic molecules and polymers in solids, thin films, and solutions." They will be presented with the award at the 2013 Materials Research Society Spring Meeting in San Francisco. The award is endowed by Toh-Ming Lu and Gwo-Ching Wang.
\end{abstract}

At the University of Delaware where Rabolt founded the Materials Science and Engineering Department, Chase and Rabolt collaborate on a number of projects related to the spectroscopic analysis of polymers, including recent work to develop methods for the rapid acquisition of spectra for such applications as inline analysis during manufacturing processes using focal plane arrays, giving rise to a new technique called planar array infrared spectroscopy (PA-IR). This approach is the basis for the University's spin-off company, PAIR Technologies LLC. The PA-IR instrument enables ultrarapid $(<100 \mu \mathrm{s})$ detailed detection and chemical analyses of polymers, chemical toxins, and biological pathogens.

Their work, however, began in separate locations with different research groups, simultaneously developing Fourier Transform Raman Spectroscopy (FTRaman). Prior to their work, the practical use of Raman spectroscopy for examining polymers was MRS severely limited due to overwhelming contributions from sample contaminants in creating a fluorescent background. Around 1985, Chase at the DuPont Central Research Laboratories in Delaware 
and Rabolt at the IBM Almaden Research Laboratory in California each developed approaches to overcome these limitations. Their work included the need to reduce the intensity of the lasers used in examining the samples to enhance signalto-noise ratios, and the development of interferometric detectors to extract the weak Raman signals that were generated. Both laboratories demonstrated that FT-Raman could be used as a powerful compliment to the more well-established
FT-IR methods. Their FT-Raman techniques revolutionized the detailed study of polymers and biopolymers in the presence of fluorescent impurities.

Shortly after publication of their seminal articles in 1986, the technique of FT-Raman was adapted by a number of commercial instrument companies including Bomem (now ABB), Bio-Rad (now Varian), Nicolet (now Thermo), Bruker, and Perkin-Elmer. Specific application areas include forensics, art and archeology, biological materials, disease diagnosis, and pharmaceuticals.

Rabolt became the founding chair of the department at Delaware where he is now active as a Karl W. and Renate Böer Named Professor. He received his $\mathrm{PhD}$ degree in chemical physics from Southern Illinois University. Chase, retired from DuPont, is now a Research Professor in the department. He received his $\mathrm{PhD}$ degree in physical chemistry from Princeton University.

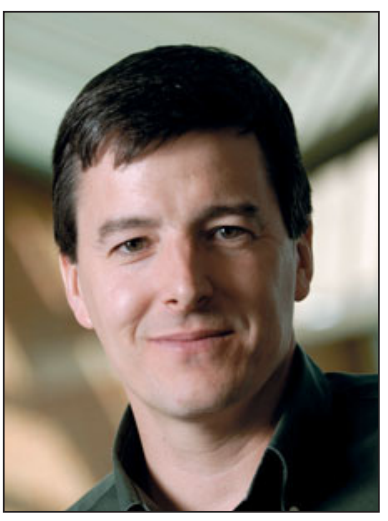

John A. Rogers receives Mid-Career Researcher Award for stretchable electronics

T he Materials Research Society (MRS) has named John A. Rogers, director of the Seitz Materials Research Laboratory at the University of Illinois at Urbana-Champaign (UIUC), to receive the Mid-Career Researcher Award for "fundamental and applied contribu-

\section{$M R S$}

tions to materials, mechanics designs, and assembly techniques for stretchable/flexible electronic systems." Rogers will be recognized during the Award Ceremony at the 2013 MRS Spring Meeting in San Francisco. The Mid-Career Researcher Award, endowed by Aldrich Materials Science, recognizes exceptional achievements in materials research made by mid-career professionals.

Rogers, who holds the Swanlund Chair at UIUC with a primary appointment in the Department of Materials Science and Engineering, changed the way researchers think about the possibilities in the field of flexible/stretchable electronics. In particular, he established comprehensive routes to semiconductor devices and integrated systems that offer the operational performance of conventional, wafer-based technologies, but with the ability to bend, fold, twist, stretch, and wrap complex, curvilinear, and time-dynamic surfaces in ways that would otherwise be impossible.

By pioneering the use of assemblies of semiconductor nanostructures, Rogers enabled electronic/optoelectronic devices to be formed on amorphous, lowtemperature substrates with performance that is superior, by several orders of magnitude, to that possible with alternative materials. The materials he used range from nanomembranes/ribbons of monocrystalline silicon and gallium arsenide to arrays/networks of single-walled carbon nanotubes as effective thin films for high-performance electronic devices.

Defining strategies to combine these classes of "hard" semiconductor elements with soft substrates (e.g., sheets of plastic or slabs of rubber), Rogers produced hybrid materials constructs with mechanical properties defined almost exclusively by the substrates. He demonstrated, for example, that ultrathin structures, in neutral mechanical plane (NMP) layouts, can impart significant levels of flexibility to materials that are intrinsically brittle, like $\mathrm{Si}$ and GaAs. He further showed that such structures can provide end-to-end stretchability. With this progress in materials and mechanics, Rogers invented new classes of deterministic assembly techniques that enable such circuits to be constructed at high throughputs and yields.

Among the most compelling application opportunities with this new class of electronics are in "tissue-like" systems that integrate non-invasively and intimately with surfaces of the human body (i.e., bio-integrated devices) and in devices that adopt biologically inspired layouts such as "eyeball" cameras that incorporate hemispherically curved arrays of silicon photodetectors to enable fields of view and levels of aberration that can only be realized in conventional planar systems by using multicomponent imaging optics. Rogers' work is also realizing commercial success, including a sports monitoring device (joint with Reebok) that was announced in 2012.

Rogers holds over 80 patents and patent applications and has over 350 publications. He received his $\mathrm{PhD}$ degree in physical chemistry from the Massachusetts Institute of Technology. His other honors include Fellow of several professional societies, including MRS; the MacArthur Fellowship; the LemelsonMIT Prize; induction into the National Academy of Engineering; and a Junior Fellowship in the Society of Fellows, Harvard University. 